\title{
Influence of Complex LCF and Dwell Load Regimes on Fatigue of Ti-6Al-4V
}

\author{
P.O.Tympel ${ }^{\mathrm{a}}$, T.C. Lindley ${ }^{\mathrm{a}}$, E.A. Saunders ${ }^{\mathrm{b}}$, M.Dixon ${ }^{\mathrm{c}}$, D.Dye ${ }^{\mathrm{a}}$ \\ ${ }^{a}$ Department of Materials, Royal School of Mines, Imperial College London, Prince Consort \\ Road, London SW7 2BP, UK \\ ${ }^{b}$ Rolls Royce plc, Materials - Failure Investigation, Bristol BS34 7QE, UK \\ ${ }^{c}$ Rolls Royce plc, Elton Road, Derby DE24 8BJ, UK
}

\begin{abstract}
Real components are usually subjected to variable amplitude fatigue, and yet the deformation micromechanisms that occur due to such load changes have barely been the subject of study. Here, unidirectionally rolled equiaxed Ti$6 \mathrm{Al}-4 \mathrm{~V}$ plate was subjected to mixed dwell and variable amplitude low cycle fatigue (LCF), with the finding that overloads near the yield stress were found to retard subsequent fatigue crack growth, whilst elastic underloads were found to accelerate subsequent growth. Dwell intervals were found to be especially damaging, to a far greater extent than either dwell or LCF alone. Dwell facets were found to initiate subsurface and to be smoother than LCF facets, but were otherwise similar in orientation ( $\sim 30^{\circ}$ to the loading axis) and crystallographic plane, $2-13^{\circ}$ from (0002). However, no alteration of the slip bands underlying striations was observed at the point of load changes using TEM. In failure investigation, striation counting is an important tool; the loading changes used were not found to affect the number of striations formed. Dislocation networks were found between similarly oriented grains in the as-received material, which disintegrated under dwell loading and at high stresses.
\end{abstract}

Keywords: Titanium alloys, Fatigue, Facets, TEM, Dislocation structures

Email address: peter.tympel10@imperial.ac.uk (P.O.Tympel) 


\section{Introduction}

Titanium alloys are widely used in aerospace gas turbines at temperatures up to around $600^{\circ} \mathrm{C}$ owing to their superior specific fatigue strength, especially for rotating parts such as rotor discs and blades [1]. In service such components 5 undergo complex loading conditions. For example during takeoff, the engine experiences a period of high spool speeds, potentially leading to the cold dwell fatigue failure regime $[2,3]$. In other parts of the flight cycle, there are other changes in loading regime and temperature, such at climb and cruise. Therefore, there is a strong practical motivation to understand how variable amplitude loading affects fatigue crack initiation and growth.

More than $85 \%$ of the lifetime of Ti- $6 \mathrm{Al}-4 \mathrm{~V}$ subject to cyclic loading can be attributed to fatigue crack initiation $[4]^{1}$. Conventionally, initiation is taken to occur at slip bands, which are continuously cycled during fatigue. Hydrogen is suspected to interact with dislocations, increasing the energy for cross slip, promoting slip bands [5]. High stress ratios (R) favour initiation at the sample surface with the formation of initiation facets. The initiation facets were found to lie around $10^{\circ}$ from the basal plane. Surface facets were tilted $30^{\circ}$, whilst subsurface facets were $30^{\circ}-60^{\circ}$ towards the loading direction [6]. The point of fracture origin is susceptible to the loading conditions and can also occur subsurface [7].

Individual cycles can leave single growth features on the fracture surface which are termed striations. During crack opening and closing, slip systems at the crack tip are activated $[8,9]$. This slip activity leads to decohesion,

\footnotetext{
${ }^{1}$ It should be noted that [4] defines initiation pragmatically, at a crack length of $0.5 \mathrm{~mm}$. For the purposes of the present work, we prefer to define initiation microstructurally, as the formation of a single cracked $\alpha_{p}$ grain, of approximate dimension $10 \mu \mathrm{m}$. Using standard $d a / d N$ curves for Ti-6Al-4V, growing a crack between these two sizes would take $\sim 20,000$ cycles at a stress level of $820 \mathrm{MPa}$, and $\sim 14,000$ cycles at $880 \mathrm{MPa}$. Therefore 'microstructural' crack initiation can be inferred to require a significant fraction of life at lower stress levels, but may occur quite quickly near the yield stress.
} 
progressing the crack by an increment $\Delta a$. Striation-like features were found to be created by two bisecting prismatic planes [10]. A single striation can be formed by a single cycle, within a particular range of $\Delta K$. For example, below $\sim 10 \mathrm{MPa} \sqrt{\mathrm{m}}$ the plastic zone size was found to be too small for striation formation [11]. Above $\sim 50 \mathrm{MPa} \sqrt{\mathrm{m}}$ the crack progression per cycle was larger than the corresponding striation separation on the fracture surface.

Cold dwell fatigue occurs at near-ambient temperature where $(\sim 120 \mathrm{~s})$ holds at load lead to large reductions in cyclic life, at stresses significantly below the yield stress. Crack nucleation is usually subsurface, with $\{0002\}$ dwell initiation facets found perpendicular to the loading axis. The $\{0002\}$ direction is the stiffest orientation, but a grain in this orientation can only slip by $\langle c+a\rangle$ 35 slip, which is hard to activate. The modified Stroh model for dwell facet formation $[2,12]$ suggests that deformation in this 'hard' grain is initiated by a dislocation pile-up in an adjacent grain that is well oriented for $\langle a\rangle$-slip. However, Brandes et al.[13] found dwell sensitivity in samples without a microstructure that had the required 'hard' to 'soft' grain combinations. Crystal plasticity finite element modelling has shown that the time dependence of the phenomenon is also important [14].

Relatively little work has been done that links these micromechanical observations to the behaviour observed in variable amplitude loading regimes. For example, after a large plastic overload, a decrement in the fatigue crack growth rate has been observed, which was attributed to shielding by the crack tip plastic zone $[15,16,17,18]$. However, evidence for this proposition has not been advanced from TEM observations, most likely because, until recently, it was very difficult to extract TEM foils from fracture surfaces. In addition, most such studies examined long cracks grown from notches $(d a / d N$ vs. $\Delta K)$, and 50 so the applicability of these concepts to smaller overloads, or even to intervals of reduced loading, has yet to be established. Finally, the effect on short crack initiation and growth has yet to be studied.

In the present study we attempt to address these gaps in our understanding by examining the effect of relatively small load changes, and of transitions 
from low cycle to dwell fatigue loading, on the fatigue behaviour of un-notched, naturally initiated cracks in Ti-6Al-4V. After testing, the fracture surfaces were examined and the underlying dislocation structures observed in both initiation facets and the striations occurring during load changes.

\section{Experimental Procedure}

Unidirectionally rolled Ti-6Al-4V was employed, which had been forged in the $\beta$ field, rolled in the $\alpha+\beta$ and then creep flattened. The microstructure consisted of a near equiaxed $\alpha$-Ti with an average grain size of $10.1 \mu \mathrm{m}$, Figure 1a. An EBSD map of the cross section can be seen in Figure 2. Macrozones of similarly oriented $\alpha$-Ti grains were found, extending in the rolling plane and up to $150 \mu \mathrm{m}$ thick in the normal direction (ND). The macrozone texture was identified as $\{11 \overline{2} 0\}\langle 0002\rangle \quad[19]$. Grains within that zone have the c-axis aligned with the transverse direction (TD) of the material. Grains outside these macrozones have a $\{10 \overline{1} 0\} 0002$ texture with the $\langle 0002\rangle$ plane normal in the rolling direction. Threaded cylindrical samples were used with a $2.5 \mathrm{~mm}$ gauge diameter, and the loading direction parallel to the TD. The samples were surface ground after turning in the lathe, and then hand-polished using colloidal silica in an attempt to minimise the effects of surface roughness and any residual stresses introduced by turning.

[Figure 1 about here.]

[Figure 2 about here.]

A series of baseline low cycle fatigue (LCF) tests were conducted using a $100 \mathrm{kN}$ servohydraulic testing machine, along with tests employing alternating blocks at the same loads, Figure 1b. A 1-1-1-1 loading cycle was utilised in load control, loading in $1 \mathrm{~s}$, holding at stresses of $820 \mathrm{MPa}, 880 \mathrm{MPa}$ and $940 \mathrm{MPa}$ 80 for $1 \mathrm{~s}$ ( $2 \mathrm{~min}$ for dwell), then unloading in $1 \mathrm{~s}$, and holding at $20 \mathrm{MPa}$ for $1 \mathrm{~s}$. The variable amplitude block loading tests were combinations of LCF $880 \mathrm{MPa}$ with $820 \mathrm{MPa}, 940 \mathrm{MPa}$ and dwell, Table 1. 
Fracture surfaces were observed using a Zeiss Auriga dual beam FIB-FEGSEM with an integrated Bruker EBSD camera. Dislocation analysis was performed with a JEOL 2000FX $200 \mathrm{kV}$ TEM. Site specific foils of surface features were prepared by lift out using a dual-beam Helios NanoLab 600 FIB-FEGSEM. Non-site specific foils were prepared by thinning and electro polishing with a solution of $3 \%$ Perchloric acid, $57 \%$ Methanol and $40 \%$ Butan-1-ol at $-50^{\circ} \mathrm{C}$.

Quantitative tilt fractography (QTF) was used to calculate the spatial orientation of features on the fracture surface, as described by Sinha et al. [20]. Two SEM images at the same magnification, but two different stage tilts, are made. In both images four reference points, three forming the feature plane and one as coordinate origin, must be identified. The coordinates of the reference points are then used to calculate the plane normal. When the chosen reference point acting as origin is alternated, 4 different planes of the facet can be calculated, giving information about the shape of the fracture feature. The standard deviation of the 4 planes was used as an indication of the degree of curvature of the features.

\section{Results}

3.1. Fracture overview

[Table 1 about here.]

The failure endurance and fractographic behaviour are summarised in Table 1. Repeat testing of the 820 and $880 \mathrm{MPa}$ LCF samples gave lives of 129,500 and 25,836 cycles, respectively. The endurance at $820 \mathrm{MPa}, 880 \mathrm{MPa}$ and 940 MPa was approximately $280 \mathrm{k}, 22 \mathrm{k}$, and $10 \mathrm{k}$ cycles, respectively. Dwell fatigue loading at $880 \mathrm{MPa}$ resulted in a life that was only $\sim 40 \%$ of the LCF life at the same stress. The combined block loading samples were not found to obey Miner's rule especially well [9]. The application of overloads in test Z (LCF $880 / 940,100 \mathrm{~A} / 10 \mathrm{C})$, resulted in $21 \%$ greater life than if conditions $\mathrm{A}$ and $\mathrm{C}$ were applied alone; $(21642 / 21843+2160 / 9613)=C_{\text {Miner }}=1.21$. Similarly, blocks of reduced loading relative to the reference stress of $880 \mathrm{MPa}$ in test $\mathrm{Y}$ 
were found to be damaging, giving $C_{\text {Miner }}=0.76$, whilst the periodic dwells in test $\mathrm{X}$ were also damaging, $C_{\text {Miner }}=0.42$.

When tested at stresses below $940 \mathrm{MPa}$, the crack leading to failure initiated tests at 880 and $940 \mathrm{MPa}$ (A and C). In those two cases, the initiation sites were torn, curved and showed crack arrest marks; nucleation appeared to have occurred at a surface asperity. In general, the initiating facets were similar in size to the diameter of the $\alpha$-Ti grains, suggesting transgranular fracture along 135 a crystallographic plane. In the LCF 880/940 sample (Z), slip traces could be observed but in the other cases, the initiation facets were smooth. The subsurface facets appear smoother with less curvature than surface facets. The dwell 880 facet was the only one that showed no signs of plastic deformation; we suggest that the step observed was due to an adjacent, similarly-oriented $\alpha$ 140 at the surface, whilst at $940 \mathrm{MPa}$ the initiating crack was subsurface. The combination of different LCF block loads always resulted in a failure by surface initiation. Under dwell, at least 9 subsurface initiation sites were identified. In combination with LCF loads, over twice as many subsurface initiation sites could be observed. As seen in the overview SEM images in Figure 3, subsurface initiated cracks grow along the rolling direction, forming needle-like features on the fracture surface. Those features varied in length as well as in their position along the gauge length. The largest on the Dwell 880 sample (D) was $1.35 \mathrm{~mm}$ long. On the LCF/Dwell sample (X), two large propagated cracks were found, having a length of $1.16 \mathrm{~mm}$ and $0.86 \mathrm{~mm}$. In contrast, surface initiated cracks grew semi-elliptically towards the sample centre.

[Figure 3 about here.]

\subsection{Fracture initiation facets}

[Figure 4 about here.]

The initiation sites of the major cracks are shown in Figure 4. Generally, smooth initiating facets were observed, except for the two higher stress LCF grain. 
Surface initiated cracks also formed growth facets at distances up to $150 \mu \mathrm{m}$ from the initiation site. Growth facets were found to be more structured, with ridges, step-to-step complementary and non-complementary features. The plane of fracture was measured by means of TEM foil liftouts and a combination of quantitative tilt fractography (QTF) with electron backscatter diffraction (EBSD).

The facet normal and (0002) pole of the facets with respect to the sample coordinate system are displayed in a stereographic projection in Figure 5. The point $\left(0^{\circ}, 90^{\circ}\right)$ is the loading direction, coincident with the transverse direction (TD) of the rolled plate material. The $x$-axis is the angle between the facet normal (or (0002) pole) towards the rolling direction when projected on a plane orthogonal to the normal direction. The coordinates $\left(90^{\circ}, 0^{\circ}\right)$ corresponds to the rolling direction. The $y$-axis is the angle between the facet normal (or (0002) pole) to the normal direction. The normal direction is given by the coordinates $\left(0^{\circ}, 0^{\circ}\right)$. The spatial orientation of the facet is shown as a green cross, with the size of the cross corresponding to the variation in facet normal (small indicates a smooth, planar facet). The colour coded contours show the (0002) pole measured using EBSD. To visualise the amount of misorientation between fracture plane and basal pole, 3 circles of $5^{\circ}, 10^{\circ}$ and $15^{\circ}$ misorientation are drawn around the fracture plane. It should be pointed out to the reader that although this projection shows the same features as in Figure 4, those SEM images were not taken with the rolling and normal directions parallel to the microscope axis.

[Figure 5 about here.]

None of the initiation sites were found to be perpendicular to the loading direction. On average, the surface and subsurface initiation sites were found at inclinations of $25.9^{\circ}$ and $34.5^{\circ}$, respectively. Furthermore, the subsurface facets were flatter than the surface ones, indicated by an extremely small green cross. The contour lines of the basal poles of the facets show two distinct peaks in 170 several samples. Consequently, a single facet can consist of more than just one 
$\alpha_{p}$ grain. The average misorientation between the (0002) pole and the plane of fracture was found to be $6.4^{\circ}$ in surface facets and $5.2^{\circ}$ in subsurface facets. For selected facets, TEM foils were lifted out and the misorientation between (0002) plane and fracture plane measured. The results compared to QTF/EBSD are presented in Table 2. The misorientations measured with TEM correlate well with the data from QTF/EBSD. However, the TEM technique is only able to acquire data for the specific site from which foil was taken; in cases where a facet was formed by more than one grain, TEM data from only one grain was acquired.

\subsection{The spatial orientations of initiation and propagation features}

A comparison between the spatial orientation of crack initiation and propagation features of the samples loaded to $880 \mathrm{MPa}(\mathrm{A}, \mathrm{D}, \mathrm{X})$ can be seen in Figure 6 . Propagation facets formed by LCF fatigue showed the largest average tilt from the loading direction of $38.1^{\circ}$, followed by Dwell/LCF 880 initiation $\left(33.2^{\circ}\right)$, Dwell 880 initiation $\left(31.4^{\circ}\right)$ and striated grains $\left(20.8^{\circ}\right)$. Strikingly, propagation facets in LCF showed no preferred orientation, except that they tended to face towards the crack initiation site. In contrast, the striated surface normals tended to cluster in the ND-TD plane, close to the TD - which was the loading axis. It may be significant that, for the $\{0002\} \| R D$ macrozones, these striation orientations are consistent with the available prism $\langle a\rangle$ slip planes. Dwell initiation facets were near-TD and (0002), but inclined towards the RD. However, in combined LCF/dwell these initiation facets showed a much greater spread of orientations.

\subsection{Striated crack growth}

The formation of fatigue striations was observed in samples with an LCF component. In purely LCF loaded samples, at a distance of $60-180 \mu \mathrm{m}$ from the 
initiation, striations began to be observed. The striation separation progres-

cycles the rate of crack propagation seemed to have reduced by the presence of $940 \mathrm{MPa}$ overloads and increased when underloads of $820 \mathrm{MPa}$ were applied. The rate of crack propagation during the underloads themselves seemed not to 
change due to the presence of the $880 \mathrm{MPa}$ block loads. For the $940 \mathrm{MPa}$ over-

\subsection{Dislocation networks}

Apart from fractography, the focus of this work lies in the dislocation analysis of the fracture initiation sites and propagation features. The as-received material showed mainly $\langle a\rangle$-type dislocations on prismatic and pyramidal slip planes. Dislocation network structures such as the one seen in Figure 9a were observed in multiple grains. $\mathbf{g} \cdot \mathbf{b}$ and trace analysis showed that three dislocations periodically form nodes, forming a net. The dislocations were identified as $(0 \overline{1} 10)[2 \overline{1} \overline{1} 0],(1 \overline{1} 01)[11 \overline{2} 0]$ and $(10 \overline{1} 1)[1 \overline{2} 10]$ screw dislocations. Networks were found in grains with different orientations and are easy to identify, making them a good structure to investigate the effect of different fatigue loads.

[Figure 9 about here.]

The deformation of the dislocation network under continuous cycling and dwell loads was investigated by preparing TEM foils from the gauge section, several $\mathrm{mm}$ from the fracture surface. The LCF $820 \mathrm{MPa}$ sample (B) was selected as a representative of continuous loading, and compared with the dwell $880 \mathrm{MPa}$ sample (Z). As seen in Figure 9b, the network shows no sign of deformation after $820 \mathrm{MPa}$ cyclic fatigue. The network was again found to be formed by $\langle a\rangle$-type screw dislocations on pyramidal and prismatic planes. A QTF study showed that the networks lay close to the $\{1 \overline{1} 02\}$ plane, with a similar dislocation density to that of the as received material. Dislocation aggregation at the grain boundary indicated a degree of plastic deformation in the gauge section. 
In strong contrast to this is the network after dwell at $880 \mathrm{MPa}$ as seen in Figure $9 \mathrm{c}-\mathrm{d}$. The network of $\langle a\rangle$-type screw dislocations was less homogeneous in cell size and showed distortion and defects around the edges. Also, the network was surrounded by paired dislocations (double lines) with darker contrast. The paired dislocations were found to be of $\langle a+c\rangle$-type lying on pyramidal slip planes. They showed evidence of cross slip between pyramidal planes and were observed near the edge of the network.

\subsection{Dislocation structure within initiation facets}

The results of the dislocation study of the subsurface facet causing the LCF $940 \mathrm{MPa}$ sample (D) to fail are shown in Figure 10. An overview of the facet forming grain revealed slip bands of $\langle a\rangle$-type screw character on the (0110),

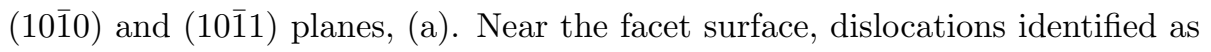
$\langle a\rangle$-type edge or $\langle c+a\rangle$-type were found (b). Most of these dislocations were curved, but overall they were found to follow the trace of the basal plane. It can be clearly seen that these change to different basal slip planes by forming jogs. Below the surface a heavily distorted network can be seen (d). The network was almost completely untangled and only a few irregular sized cells remained.

[Figure 10 about here.]

The formation of slip bands could not be observed in the subsurface initiation facet found in the LCF $820 \mathrm{MPa}$ sample (B), Figure 11a. Near the surface, curved edge dislocations with an $\langle a\rangle$-type Burgers vector were found. The edge dislocations were almost exclusively found at the fracture surface near a grain boundary (b \& c). Below the fracture surface, undeformed and deformed networks were visible (d). Dislocation analysis on surface initiation facets was also attempted. However, the dislocation density was found to be so high that it was impossible to identify them individually. Furthermore, the grain showed so much deformation that it was impossible to have the same diffraction condition over the whole grain.

[Figure 11 about here.] 


\subsection{The dislocation structure in striated, block-loaded grains}

To investigate the dislocation mechanisms involved during changes in loading regime, TEM foils of striated grains from the LCF 880/820 sample (Y) and LCF/Dwell 880 sample (X) were prepared, Figure 12. The foils were lifted from

[Figure 12 about here.]

\section{Discussion}

\subsection{Facet crystallography}

LCF facets formed during crack initiation or propagation. The first obvious difference was that dwell initiation facets were generally subsurface whilst LCF initiation facets were at the surface. The observed tilts were higher in the subsurface than in the surface facets. During crack propagation this order changed. while dwell propagation facets are reported to exhibit a smaller tilt of $\sim 10^{\circ}$ $[20,22]$. The dimensions and orientation of dwell propagation facets suggested that they formed in a macrozone. The small inclination of the facet normal to 
loading direction caused the macrozone to glint, which was visible to the naked eye. Contrary to this were the observations of Sinha et al. [22, 20]. There, facets formed by continuous cycling were reported to be almost normal to the loading direction, while dwell fatigue facets showed small tilt of $\sim 15^{\circ}$. The fact that Sinha did not distinguish between initiation or propagation facets can be seen as the reason for this discrepancy. The difference between dwell propagation and initiation facets has previously been pointed out by Pilchak and Williams [23]. The observations made here on initiation features are consistent with this work.

The crystallographic plane of the crack initiating grain did not differ between dwell and LCF. The grains fracture near the (0002) plane, which has been documented $[24,22,20]$. The misorientation is reported to be smaller in facets 325 formed by continuous cycling than dwell facets, but the difference in misorientation found here was too small for a clear distinction between the load regimes. Moreover, this study has shown that facets can be formed that span more than just one grain. In such circumstances, it is impossible to determine which grain initiated facet formation. To emphasise the point, the smallest misorientation was found in an LCF facet, but so was the largest.

When the applied stress increased, the fractographic distinction between dwell and LCF disappeared. At the highest tested LCF stress of $940 \mathrm{MPa}$, the fracture initiation behaviour changed into a subsurface initiation typical for the tested dwell samples. Furthermore, a long needle like structure was seen close to the initiation, thought to be associated with a macrozone. Consequently, as the stress was increased the fracture became more "dwell-like". In all observed facets the average misorientation was smaller than $\sim 15^{\circ}$, which is the angle between the $\{10 \overline{1} 7\}$ hydride habit plane and the (0002). Pilchak et al. [5] observed a dwell propagation facet that fractured at this misorientation in $\mathrm{Ti}$ 340 8Al-1Mo-1V. Pilchak et al. found small particles on the dwell facets which were argued to be hydrides. In the present study, the dwell subsurface initiation facet did not fracture near the hydride habit plane, nor were there particles found. An influence of hydrogen on initiation of dwell or LCF facetting is therefore not indicated by the present work. However, the propagation of dwell facetting 


\subsection{Spatial orientations}

Striated grains showed generally smaller tilts than any faceted feature. Moreover, their normal was tilted relative the rolling direction. This preferential tilt is thought to be a result of the texture. As seen in Figure 2 the majority of rolling direction and $\{11 \overline{2} 0\}$ along the normal direction. These are the 'hard'oriented macrozones. In contrast, 'soft'-oriented macrozones have their basal plane along the rolling direction. Bantounas et al. [26] found that the $c$-axis of striated grains was tilted towards the loading direction in a range of $55-87^{\circ}$. zones, with their $\{0002\}$ in the $\mathrm{RD}$.

A preferential spatial orientation was also found in the subsurface initiation facets caused by dwell. These were tilted $\sim 30^{\circ}$ from the transverse direction, with a near- $(0002)$ facet plane $\left(<10^{\circ}\right.$ away). This orientation is inconsistent with the facets being perfectly TD-oriented, i.e. from the hard-oriented macrozones. Instead, it suggests that the dwell subsurface initiation facets form from grains in soft macrozones; consistent with the Stroh model these would be at the hard/soft macrozone boundary.

Apart from the fact that dwell in combination with LCF increased the number of initiation sites, the facet spatial orientation did not change. The subsurface initiation behaviour of the dwell facets was found to be the crucial factor. The fact, that the LCF 880 propagation facets seemed to populate one quadrant of the stereographic projection, could indicate a preferential orientation - with facets tilted towards the crack nucleation site.

\subsection{Crack propagation}

Under dwell the crack grew mainly along macrozones. The facet propagation speeds have been reported to be between 2 and $20 \mu \mathrm{m}$ per cycle and almost 
independent of $\Delta K[5,13]$. In some cases dwell facets propagate up to two orders of magnitude faster than cyclic striations [25]. This means that just after initiation, the crack propagates along a macrozone and could stretch along the whole sample within a few hundred cycles. The primary dwell faceted region was $1350 \mu \mathrm{m}$ in length and could have grown in as few as 675 cycles. Because multiple initiation occurred, each growing along a macrozone, the area supporting the applied load reduced quickly until it was below a critical threshold and fractured.

Crack growth behaviour under variable amplitude loading has been extensively studied for different metals. An overview of sequences and observed material behaviour has been provided by Doré et al. [27]. The consecutive variation in load amplitudes can be described as a series of step-up and step-down changes.

385 There, a step down change in load was found to cause a reduction in propagation speed, step up changes initially increased the growth rate, which then reduced to the standard rate for that loading. A sequence of single or multiple high stress loads has also been described in the literature as peak overloads [16]. Essentially, an overload is a large step up and step down load sequence. Depending on the overload ratio and $\Delta K$, crack propagation can either accelerate or retard.

The LCF 880/940 sample (Z) showed crack retardation in both load blocks compared to the baseline tests. Ward-Close et al. [16] argued that the overload initially speeds the crack up because of reduced crack closure near the tip. The closure is re-established during the overload block, but an increased residual compressive stress field around the crack tip remains. This then causes improved closure at the crack tip, reducing the growth speed. Also discussed in the literature is the possible blunting of the crack by overloads [28]. The initial sharp crack after a $880 \mathrm{MPa}$ cycle could have blunted after the $940 \mathrm{MPa}$ cycles, reducing the stress concentration and hence slowing the crack. However, blunting was seen to slow crack propagation only at high overloads. An effect from increased surface irregularities contributing to roughness-induced crack closure has also been observed in literature [28]. In the present case this seems unlikely, 
since no increased roughness was seen during SEM observations.

The crack growth behaviour in the LCF 880/820 sample (Y) was surprising. Crack growth in the low stress $820 \mathrm{MPa}$ blocks were not influenced by the higher loading cycle. However, crack growth acceleration during the $880 \mathrm{MPa}$ blocks was observed relative to the simple $880 \mathrm{MPa}$ LCF test. Following the logic that overloads slow a propagating crack, the $820 \mathrm{MPa}$ blocks should have shown a reduced crack growth rate. This leads to the conclusion that the stress $880 \mathrm{MPa}$ was simply not sufficient to cause enhanced residual compressive stresses at the crack tip. The $0.2 \%$ yield stress of the material is $950 \mathrm{MPa}$, hence there was not enough plastic deformation introduced at $880 \mathrm{MPa}$ to cause a retardation effect. The $880 \mathrm{MPa}$ block showed an increase in crack propagation rate which could be contributed to the initial speed-up, similar to the findings of Ward-Close et al. $[16]$.

The dislocation study carried out on the LCF 880/820 (Y) and LCF/Dwell 880 samples $(\mathrm{X})$ showed that two pyramidal slip systems were activated during striation formation. A change in striation separation could not be correlated with a change of the slip plane separation, but a deflection of the crack path was observed. This step is thought to be caused by a break up in the symmetry of the slip at the crack tip. Dislocation glide in one of the two pyramidal slip bands increased, deflecting the crack path along that plane. This effect was most pronounced in the change from continuous cycling to dwell hold. The two minute dwell allowed for so much slip that a step ten times higher than LCF striations was created. Screw dislocations are known to show time-dependent slip in Ti-6Al-4V, supporting this hypothesis [29, 30].

\subsection{Dislocation networks in the as-received material}

The dislocation networks found in the as received material are low energy configurations formed during heat treatment [31]. The network is formed by two screw dislocations on different, non-parallel planes. The parent dislocations with different Burgers vector intersect and form a third dislocation which lies on a slip plane that shares a common zone axis with the parent disloca- 
tions. The Burgers vector of the newly formed dislocation is the sum of the

\subsection{Dislocation networks after fatigue}

The network in the subsurface facet of the LCF $820 \mathrm{MPa}$ sample (B) that was found $450 \mathrm{~nm}$ below the surface showed little sign of distortion and no sign of dislocation pile ups. However, below the fracture surface the remains of a dislocation network are seen. This could be an indication that cracks propagate along networks easily. However, in the as-received material dislocation networks along the basal plane were not observed. The electro-polished foil taken from 
the gauge section of the $820 \mathrm{MPa}$ sample (B) showed that plastic deformation was limited to grains along the crack growth path.

Under dwell at $880 \mathrm{MPa}$ dislocation activity increased, as seen in the entangling of the network and pile ups of $\langle c+a\rangle$ screw dislocations. In the long dwell periods dislocations have enough time to unlock from a sessile configuration. Dislocations were seen by Zhang et al. to be transmitted through a network or absorbed by it [35]. In the present study dislocations were observed to pile up at networks and they cross slipped on a plane which was along the net. The fact that only $\langle c+a\rangle$ pile ups were found might be connected to the observation that the network dislocations were missing their $\langle c\rangle$-component dislocations, although this is speculative.

In the literature it is argued that dislocation networks form during LCF cycling [36] in Ti-6Al-4V at room temperature. Networks similar to the ones found in this work were observed after fifty cycles at $200 \pm 775$ MPa. However, Kang et al. make no comparison to network structures in the as-received material and do not show if new networks are generated by fatigue. In the present work there was no evidence visible that networks form during continuous cycling. Networks were only seen to disintegrate during dwell or by cycling at stresses near the yield strength. In dwell the networks were seen to entangle. Wang et al. has put forward the idea that dislocation networks can develop during dwell [34]. The fact that Wang also found networks prior to dwell fatigue casts doubt on that theory. In a previous high temperature compression experiment, Wang et al. reported a dislocation network consisting of two $\langle c+a\rangle$ and one $\langle a\rangle$-type screw dislocation [33]. This experiment was conducted at $1020^{\circ} \mathrm{C}$ where a dynamic generation of dislocation network by thermal activation would be possible. To prove that the networks are not only formed during heat treatment, in situ experiments would need to be carried out.

\subsection{Ordering and superdislocations}

TEM diffraction patterns have shown the presence of diffuse $\mathrm{Ti}_{3} \mathrm{Al}$ superlattice spots prior to testing. In $\mathrm{Ti}_{3} \mathrm{Al}$ dislocations are known to split into partials 
with an antiphase boundary between them [37]. Under TEM these two superpartials would be visible as a double line. This dissociation is categorised into two types - mode I (wide dissociation type: straight screw dislocation) and mode II (narrow dissociation type: curved screw dislocation) [38]. The visible double lines in the dislocation network and surrounding dislocations seen in Figure 9(cd) indicate dissociation into superpartials. The dislocations in the network are mode II partials, whilst the wider-separated $\langle 2 c+a\rangle$ pyramidal dislocations are mode I superpartials. Examples of networks formed by superpartials in $\mathrm{Ti}_{3} \mathrm{Al}$ were observed by Legros et al. [39]. Interactions between Superdislocations have been predicted to cause microcracks [40]. According to Kar'kina a reaction between an $\langle a\rangle$-type dislocation on a prismatic plane and a $\langle 2 c+a\rangle$-type on a pyramidal plane, as was the case in Figure 9c, could result in fracture along the (0002) plane.

\section{Conclusions}

Equiaxed Ti-6Al-4V UD plate has been subjected to un-notched low cycle and dwell fatigue, in order to study the effect of block loading regimes on the fatigue cracking behaviour. The following conclusions can be drawn,

1. Underloads cause an increase in crack propagation speed during subsequent reloading, whilst overloads at stresses near the yield strength slow the crack down. Individual dwell cycles during LCF were found to be especially damaging. For the conditions examined here the retardation effect of overloads could only be observed by a smaller average propagation rate per cycle, not by a reduction in the number of striations (crack arrest).

2. Initiation and propagation features could be distinguished by their preferred spatial orientation, flatness or tilt towards the tensile axis. Dwell initiation facets were smoother than LCF facets, were more inclined towards the loading direction and were always found subsurface. During propagation, dwell facets were formed within the macrozones and were 
found to be normal to the loading direction. The texture of the material resulted in a preferential spatial orientation of crack initiation and growth features.

\section{Acknowledgements}

The material used in this study was supplied by Timet during EPSRC project EP/E044700/1. DD was supported by EPSRC grants EP/H004882/1 and EP/K034332/1, and POT by a Rolls Royce plc - EPSRC DTA CASE

\section{References}

[1] Rolls-Royce, The jet engine, 5th ed., Rolls-Royce, Derby, 1996. 
[2] M. Bache, A review of dwell sensitive fatigue in titanium alloys: the role of microstructure, texture and operating conditions, Int. J. Fatigue. 25 (2003) $1079-1087$.

[3] Z. Song, D. W. Hoeppner, Dwell time effects on the fatigue behavior of titanium alloys, Int. J. Fatigue. 10 (1988) 211-218.

[4] J. A. Hall, Fatigue crack initiation in alpha-beta titanium alloys, Int. J. Fatigue. 19 (1997) 23-37.

[5] A. L. Pilchak, J. C. Williams, Observations of facet formation in near- $\alpha$ titanium and comments on the role of hydrogen, Metall. Mater. Trans. A 42A (2011) 1000-1027.

[6] S. K. Jha, C. J. Szczepanski, P. J. Golden, W. J. Porter, R. John, Characterization of fatigue crack-initiation facets in relation to lifetime variability in Ti-6Al-4V, Int. J. Fatigue. 42 (2012) 248-257.

[7] X. Liu, C. Sun, Y. Hong, Effects of stress ratio on high-cycle and veryhigh-cycle fatigue behavior of a Ti-6Al-4V alloy, Mater. Sci. Eng. A 622 (2015) 228-235.

565

[8] S. Suresh, Fatigue of materials, 2nd ed., Cambridge University Press, Cambridge, 1998.

[9] P. P. Milella, Fatigue and corrosion in metals, Springer, Milan, 2012.

[10] Y. Mine, S. Ando, K. Takashima, Crystallographic fatigue crack growth in titanium single crystals, Mater. Sci. Eng. A 528 (2011) 7570-7578.

[11] M. Caton, R. John, M. Porter, W.J. Burba, Stress ratio effectson small fatigue crack growth in Ti-6Al-4V, Int. J. Fatigue. 38 (2012) 36-45.

[12] W. J. Evans, M. R. Bache, Dwell-sensitive fatigue under biaxial loads in the near-alpha titanium-alloy IMI685, Int. J. Fatigue. 16 (1994) 443-452. 
[13] M. Brandes, M. Mills, J. Williams, The influence of slip character on the creep and fatigue fracture of an $\alpha \mathrm{Ti}-\mathrm{Al}$ alloy, Metall. Matter. Trans. A 41A (2010) 3463-3472.

[14] F. P. E. Dunne, D. Rugg, On the mechanisms of fatigue facet nucleation in titanium alloys, Fatigue Fract. Eng. M 31 (2008) 949-958.

[15] K. T. Venkateswara Rao, R. O. Ritchie, Mechanisms for the retardation of fatigue cracks following single tensile overloads: behavior in aluminumlithium alloys, Acta. Metall. Mater. 36 (1988) 2849-2862.

[16] C. M. Ward-Close, A. F. Blom, R. O. Ritchie, Mechanisms associated with transient fatigue crack-growth under variable-amplitude loading: An experimental and numerical study, Eng. Fract. Mech. 32 (1989) 613-638.

[17] S. Y. Lee, P. K. Liaw, H. Choo, R. B. Rogge, A study on fatigue crack growth behavior subjected to a single tensile overload part I. An overloadinduced transient crack growth micromechanism, Acta. Mater. 59 (2011) 485-494.

[18] S. Y. Lee, H. Choo, P. K. Liaw, K. An, C. R. Hubbard, A study on fatigue crack growth behavior subjected to a single tensile overload: Part II. Transfer of stress concentration and its role in overload-induced transient crack growth, Acta. Mater. 59 (2011) 495-502.

[19] Y. N. Wang, J. C. Huang, Texture analysis in hexagonal materials, Mater. Chem. Phys. 81 (2003) 11-26.

[20] V. Sinha, M. J. Mills, J. C. Williams, Determination of crystallographic orientation of dwell-fatigue fracture facets in Ti-6242 alloy, J. Mater. Sci. 42 (2007) 8334-8341.

[21] J. Toribio, N. Alvarez, B. Gonzalez, J. C. Matos, A critical review of stress intensity factor solutions for surface cracks in round bars subjected to tension loading, Eng. Fail. Anal. 16 (2009) 794-809. 
[22] V. Sinha, M. J. Mills, J. C. Williams, Crystallography of fracture facets in a near-alpha Titanium alloy, Metall. Mater. Trans. A 37A (2006) 2015-2026.

[23] A. L. Pilchak, J. C. Williams, Clarification of the fracture plane of dwell fatigue cracks in titanium alloys, Fatigue. Mater. (2010) 327-337.

[24] A. L. Pilchak, A. Bhattacharjee, A. H. Rosenberger, J. C. Williams, Low $\Delta K$ faceted crack growth in titanium alloys, Int. J. Fatigue. 31 (2009) 989-994.

[25] A. L. Pilchak, Fatigue crack growth rates in alpha titanium: faceted vs. striation growth, Scripta Mater. 68 (2013) 277-280.

[26] I. Bantounas, D. Dye, T. C. Lindley, The effect of grain orientation on fracture morphology during high-cycle fatigue of Ti-6Al-4V, Acta. Mater. 57 (2009) 3584-3595.

[27] M. J. Dore, S. J. Maddox, Accelerated fatigue crack growth in 6082 T651 aluminium alloy subjected to periodic underloads, Procedia. Eng. 66 (2013) 313-322.

[28] K. D. Singh, M. R. Parry, I. Sinclair, Variable amplitude fatigue crack growth behavior - a short overview, J. Mech. Sci. Technol. 25 (2011) 663673.

[29] P. Castany, F. Pettinari-Sturmel, J. Crestou, J. Douin, A. Coujou, Experi620 mental study of dislocation mobility in a Ti-6Al-4V alloy, Acta. Mater. 55 (2007) 6284-6291.

[30] S. Farenc, D. Caillard, A. Couret, An in situ study of prismatic glide in $\alpha$ Titanium at low temperatures, Acta. Metall. Mater. 41 (1993) 2701-2709.

[31] F. J. Humphreys, M. Hatherly, Recrystallisation and related Annealing 625 phenomena, Elsevier, Oxford, 2004, pp. 91-119.

[32] S. P. Agrawal, G. A. Sargent, H. Conrad, Hexagonal dislocation networks in Titanium, Metall. Trans. 5 (1974) 2415-2422. 
[33] X. Wang, M. Jahazi, S. Yue, Substructure of high temperature compressed titanium alloy IMI 834, Mater. Sci. Eng. A 434 (2006) 188-193.

[34] X. Wang, P. Vo, M. Jahazi, S. Yue, Dwell fatigue microstructure in a near- $\alpha$ Titanium alloy, Metall. Mater. Trans. A 38 (2007) 831-839.

[35] J. P. Zhang, H. C. Gu, H. J. Zhou, S. F. Zhang, C. Laird, Substructures and their changes in high purity Titanium during tensile deformation, Mater. Sci. Eng. A 119 (1989) 33-39.

[36] G. Z. Kang, Y. W. Dong, Y. J. Liu, H. Jiang, Macroscopic and microscopic investigations on uniaxial ratchetting of two-phase Ti-6Al-4V alloy, Mater. Charact. 92 (2014) 26-35.

[37] Y. Koizumi, T. Nakano, Y. Umakoshi, Dislocation dipoles in cyclically deformed $\mathrm{Ti}_{3} \mathrm{Al}$ single crystals, Intermetallics 8 (2000) 179-186.

[38] M. Legros, A. Couret, D. Caillard, Comparison of glide mechanisms in hcp Ti and $\mathrm{Ti}_{3} \mathrm{Al}$, J. Mater. Sci. 41 (2006) 2647-2657.

[39] M. Legros, A. Couret, D. Caillard, Prismatic and basal slip in $\mathrm{Ti}_{3} \mathrm{Al}$ II. Dislocation interactions and cross-slip processes, Philos. Mag. A 73 (1996) 81-99.

${ }_{645}$ [40] L. E. Kar'kina, L. I. Yakovenkova, Nucleation of microcracks during dislocation interactions in a $\mathrm{Ti}_{3} \mathrm{Al}$ single crystal, Phys. Solid. State 50 (2008) 1061-1070. 


\section{List of Figures}

1 Equiaxed microstructure of as-received Ti-6Al-4V material viewed

650 along rolling (RD), transverse (TD) and normal (ND) directions (a). Schematic load profile of simple baseline experiments and variable amplitude ("block") loading (b). . . . . . . . . . . 28

2 EBSD map of the as-received material, separated into two maps, (left) grains with a hard crystallographic orientation and (right) grains with a soft orientation. Macrozones are visible as alternating layers of similarly oriented $\alpha$-Ti grains; some $\{0002\} \|$ TD (left) and others $\{0002\} \|$ RD (right) . . . . . . . . . . . . 29

3 Examples of the fracture surfaces, highlighting the initiation sites of the cracks leading to failure (IN), and an EBSD map of the asreceived material. In samples that failed from a surface nucleating crack, the fracture grew semi-elliptically into the material with little influence from the macrozones. Subsurface initiated cracks were observed in the dwell fatigued samples; these grew along rolling direction, causing needle-like features on the fracture surface. 30

4 Overview of the surface and subsurface initiation sites. The initiation occurred transgranularly, resulting in smooth facets similar in diameter to the $\alpha$-Ti grains. Surface initiated facets appear more curved, with growth marks, when initiated at an asperity. Indications of slip traces could be readily seen in the initiating facet in the LCF 880/940 sample (Z). . . . . . . . . . . . . . 31

5 Stereographic projection of the spatial orientation of the facet normals and (0002) poles. The origin coincides with the loading direction. The spatial orientation and variation of the facet normal is shown by the position and size of the green cross. The contour lines show the (0002) pole of the facets. Three circles with $5^{\circ}, 10^{\circ}$ and $15^{\circ}$ misorientation are drawn around the facet normal. All the observed facets were between $21.7^{\circ}$ and $35.4^{\circ}$ from the loading direction. Although the surface initiation facets possessed a smaller inclination to the loading direction, the misorientation between (0002) plane and fracture plane was similar.

$6 \quad$ Stereographic projection of the facet orientations measured with QTF, for samples loaded to $880 \mathrm{MPa}$ (A - LCF only, C - dwell only, X - LCF/Dwell). . . . . . . . . . . . . . . . . . 33

7 Observed change in striation separation in sample LCF 880/820 $(\mathrm{Y})$, due to a change in fatigue stress. . . . . . . . . . . . 34 
8 Measured striation separation vs. calculated stress intensity, comparing crack propagation under simple low cycle fatigue crack growth to that obtained under combined block loading (starred *). (a) and (c) compare the LCF 880 sample (A) to the $880 \mathrm{MPa}$ LCF portions of block loading of samples $\mathrm{Y}$ and $\mathrm{Z}$. (b) compares the low stress LCF sample B to the under load portions of block loaded sample Y, whilst (d) compares the high stress LCF sample $\mathrm{C}$ to the over load portions of block loaded sample Z. It should be noted that all the samples failed at similar overall crack lengths; the differences in $\Delta K$ are a consequence of the differing crack shapes. . . . . . . . . . . . . . . . . . .

9 Dislocation network in $\alpha$-Ti grain in the as received material (a). The network is formed by dislocations on different slip planes which were found to be $(0 \overline{1} 10)[2 \overline{1} \overline{1} 0],(1 \overline{1} 01)[11 \overline{2} 0]$ and (1011)[1210]. After continuous cycling at $820 \mathrm{MPa}$ the network found in the gauge section remained undeformed (b). After dwell loading the network was observed to unravel (c-d). Around the network edge, $\langle a+c\rangle$-type dislocations accumulate and cross slip along the network. At higher magnification it can be seen that the dislocations in the network are paired $(\mathrm{d}) \ldots \ldots$. . . . . .

10 FIB lift out foil of the subsurface initiation facet from the sample

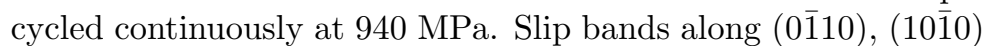
and $(10 \overline{1} 1)$ of $\langle a\rangle$-type screw dislocations formed (a). Along the fracture surface edge dislocations with $\langle a\rangle$-type Burgers vector formed (b). These edge dislocations lay in the basal plane and were also found close to an adjacent basal plane (c). A distorted network was also found below the fracture surface (d). . . . . .

11 FIB lift out foil of the subsurface initiation facet from the sample cycled continuously at $820 \mathrm{MPa}$. The formation of slip bands could not be seen in overview images (a). Dislocations of edge $\langle a\rangle$ or screw $\langle a+c\rangle$-type dislocations appeared near the surface (b) and sporadically in the bulk of the grain (c). Dislocation networks were found at the fracture surface and also below (d). . 38

12 TEM lifted foils of sample LCF 880/820 (a) and LCF/Dwell 880 (b). In both striated grains slip on the pyramidal planes occurred. The change in load regime caused a small deflection of the growing crack in the form of a depression in the LCF 880/820 sample. The 2 minute hold in the LCF/Dwell sample caused the formation of a large step which was found to be $\sim 10$ times larger 
13 Formation mechanism of a hexagonal dislocation junction which led to the formation of the network shown in Figure 9a. Two dislocations on the (1011) and (1101) planes that are close to each other build a connecting dislocation on the (0110) plane. The Burgers vector of the new segment is the sum of the two parent dislocation formed according to the reaction $\frac{1}{3}[11 \overline{2} 0]+\frac{1}{3}[1 \overline{2} 10]=$ $\frac{1}{3}[2 \overline{1} \overline{1} 0]$. The growth of the connecting dislocation reduces the overall dislocation length and hence reduces the stored energy. 
a)

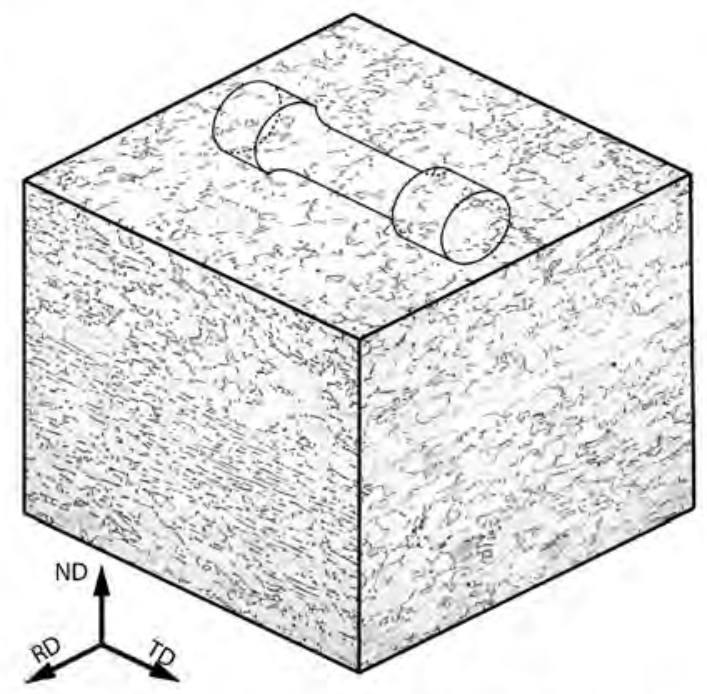

b)

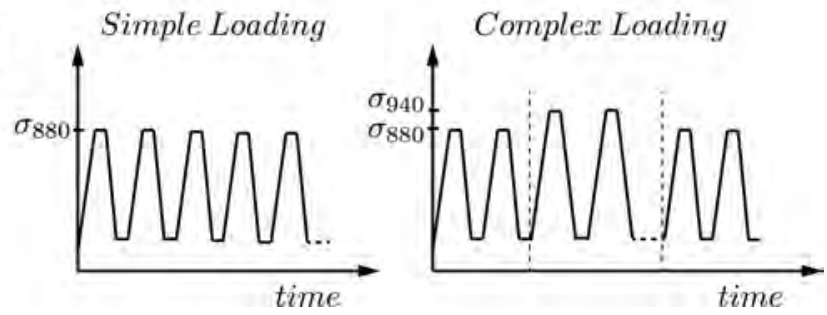

Figure 1: Equiaxed microstructure of as-received Ti-6Al-4V material viewed along rolling (RD), transverse (TD) and normal (ND) directions (a). Schematic load profile of simple baseline experiments and variable amplitude ("block") loading (b). 


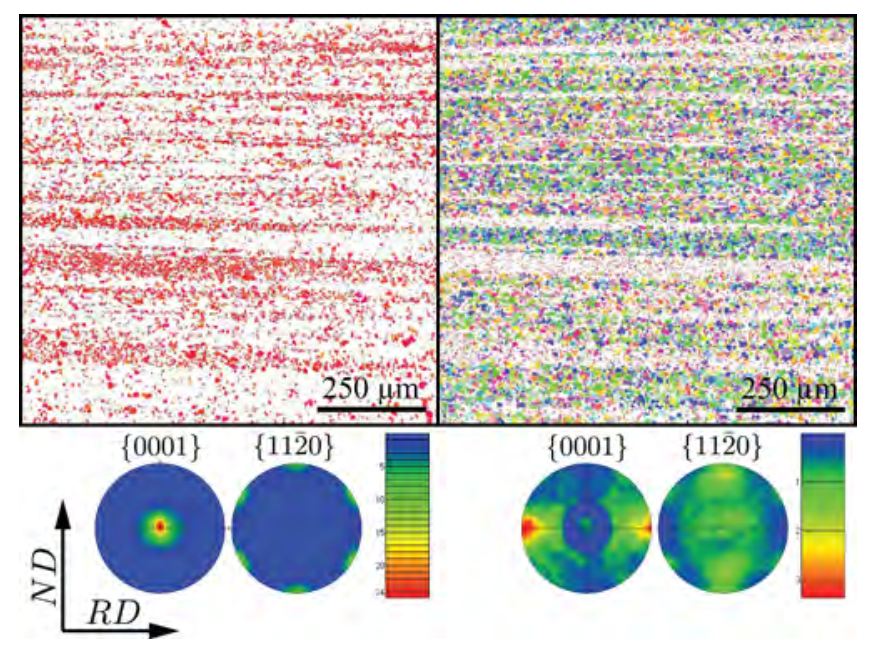

Figure 2: EBSD map of the as-received material, separated into two maps, (left) grains with a hard crystallographic orientation and (right) grains with a soft orientation. Macrozones are visible as alternating layers of similarly oriented $\alpha$-Ti grains; some $\{0002\} \| \mathrm{TD}$ (left) and others $\{0002\} \| \mathrm{RD}$ (right). 

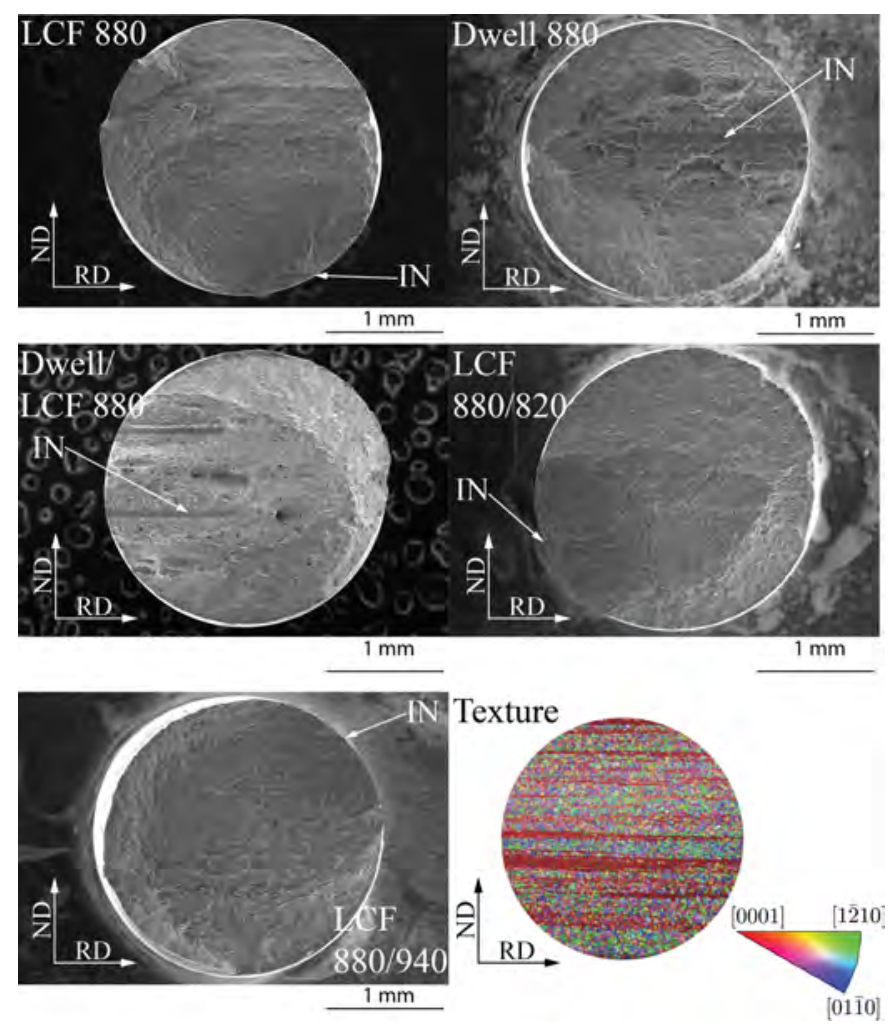

Figure 3: Examples of the fracture surfaces, highlighting the initiation sites of the cracks leading to failure (IN), and an EBSD map of the as-received material. In samples that failed from a surface nucleating crack, the fracture grew semi-elliptically into the material with little influence from the macrozones. Subsurface initiated cracks were observed in the dwell fatigued samples; these grew along rolling direction, causing needle-like features on the fracture surface. 


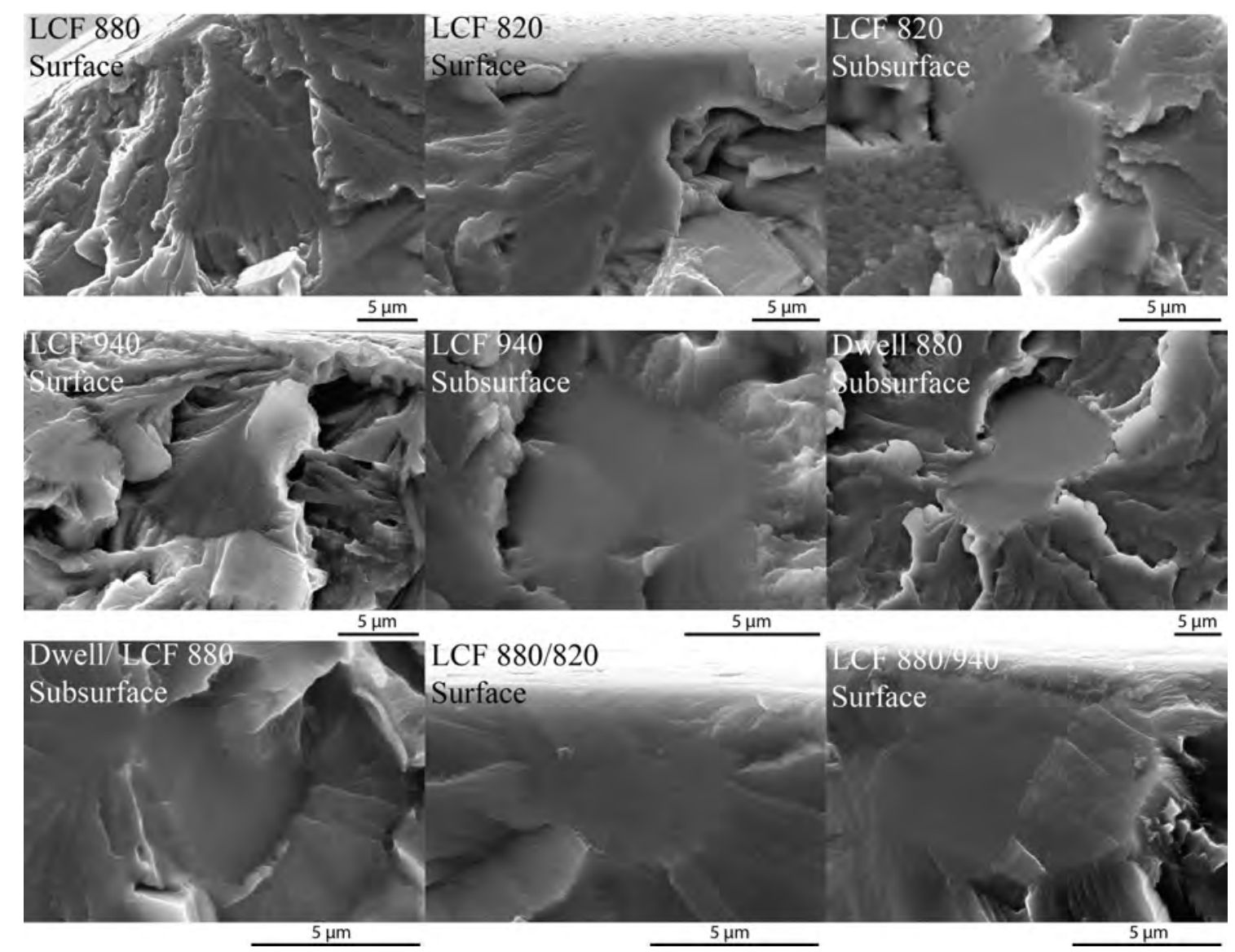

Figure 4: Overview of the surface and subsurface initiation sites. The initiation occurred transgranularly, resulting in smooth facets similar in diameter to the $\alpha$-Ti grains. Surface initiated facets appear more curved, with growth marks, when initiated at an asperity. Indications of slip traces could be readily seen in the initiating facet in the LCF 880/940 sample (Z). 


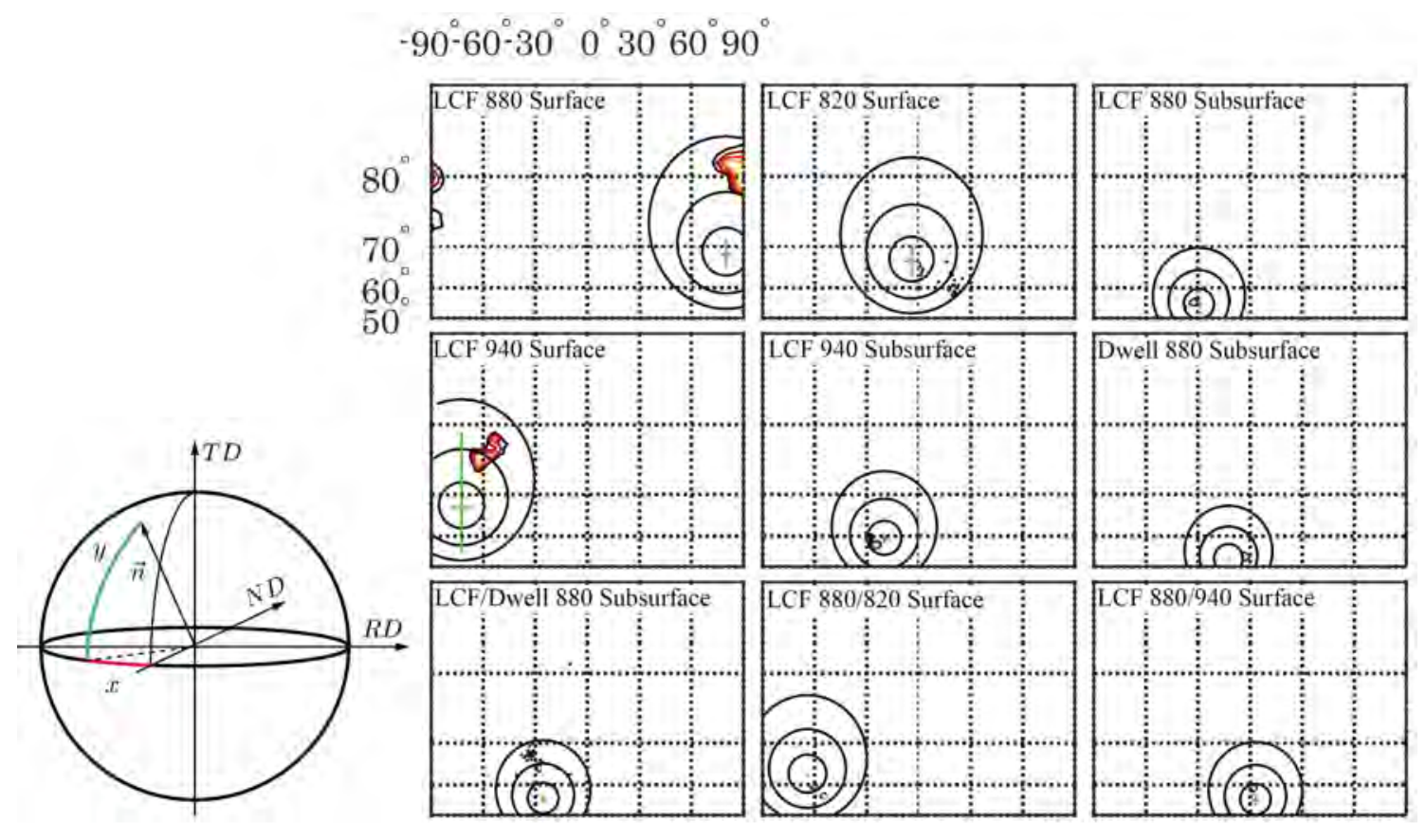

Figure 5: Stereographic projection of the spatial orientation of the facet normals and (0002) poles. The origin coincides with the loading direction. The spatial orientation and variation of the facet normal is shown by the position and size of the green cross. The contour lines show the (0002) pole of the facets. Three circles with $5^{\circ}, 10^{\circ}$ and $15^{\circ}$ misorientation are drawn around the facet normal. All the observed facets were between $21.7^{\circ}$ and $35.4^{\circ}$ from the loading direction. Although the surface initiation facets possessed a smaller inclination to the loading direction, the misorientation between (0002) plane and fracture plane was similar. 


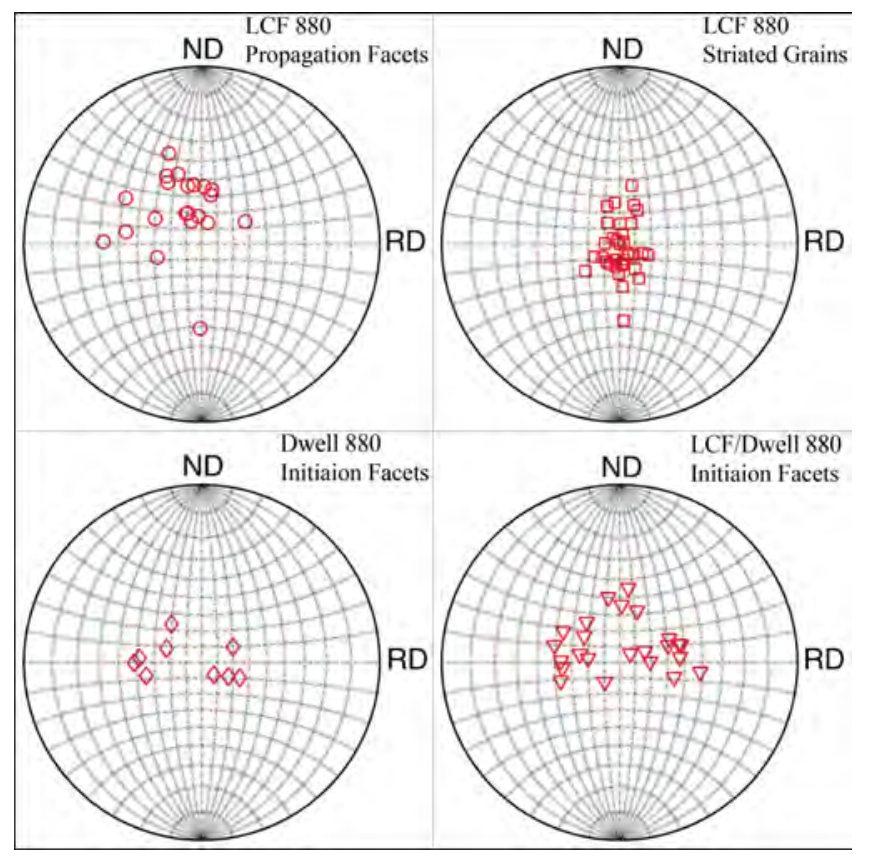

Figure 6: Stereographic projection of the facet orientations measured with QTF, for samples loaded to $880 \mathrm{MPa}$ (A - LCF only, C - dwell only, X - LCF/Dwell). 


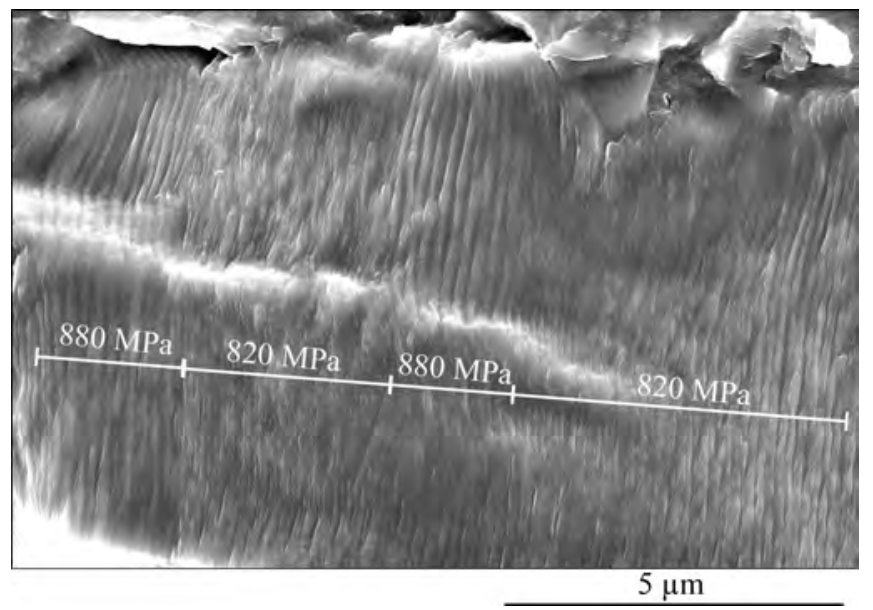

Figure 7: Observed change in striation separation in sample LCF 880/820 (Y), due to a change in fatigue stress. 

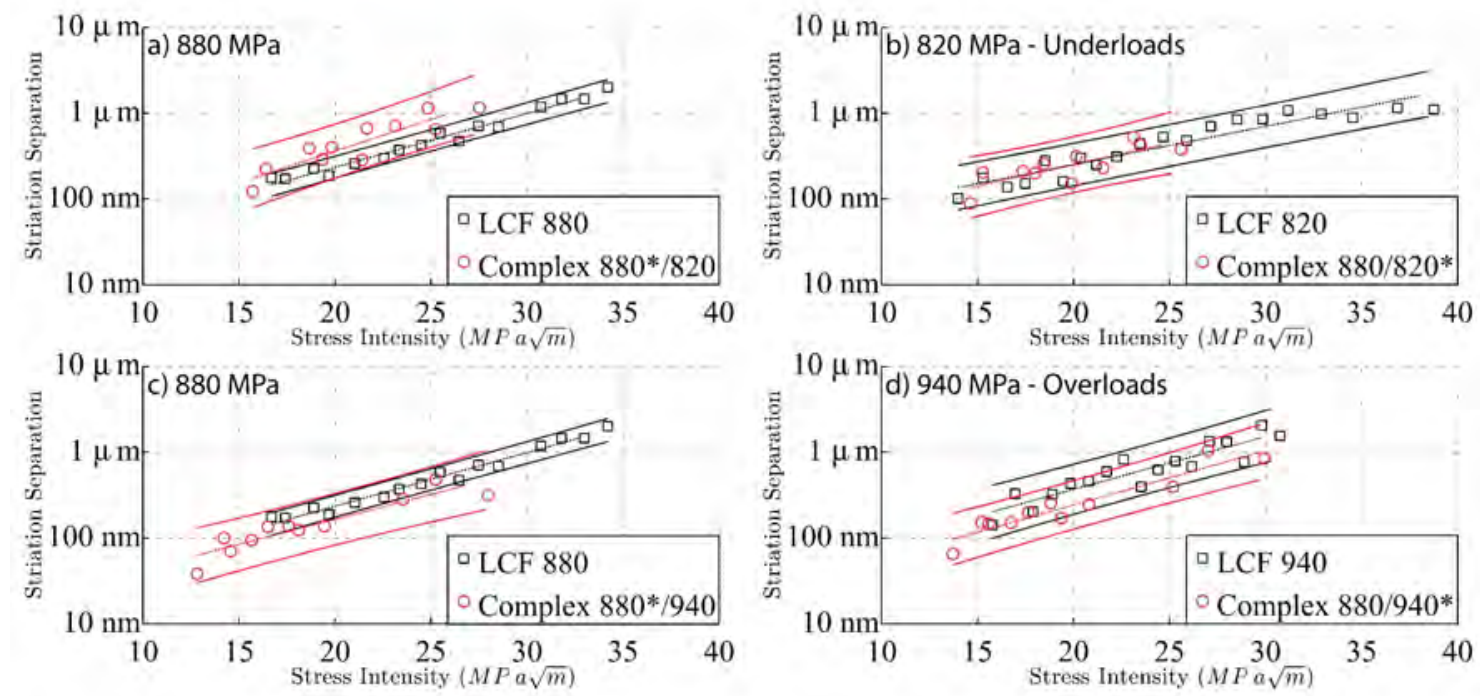

Figure 8: Measured striation separation vs. calculated stress intensity, comparing crack propagation under simple low cycle fatigue crack growth to that obtained under combined block loading (starred *). (a) and (c) compare the LCF 880 sample (A) to the $880 \mathrm{MPa}$ LCF portions of block loading of samples $\mathrm{Y}$ and $\mathrm{Z}$. (b) compares the low stress LCF sample B to the under load portions of block loaded sample Y, whilst (d) compares the high stress LCF sample $\mathrm{C}$ to the over load portions of block loaded sample $\mathrm{Z}$. It should be noted that all the samples failed at similar overall crack lengths; the differences in $\Delta K$ are a consequence of the differing crack shapes. 


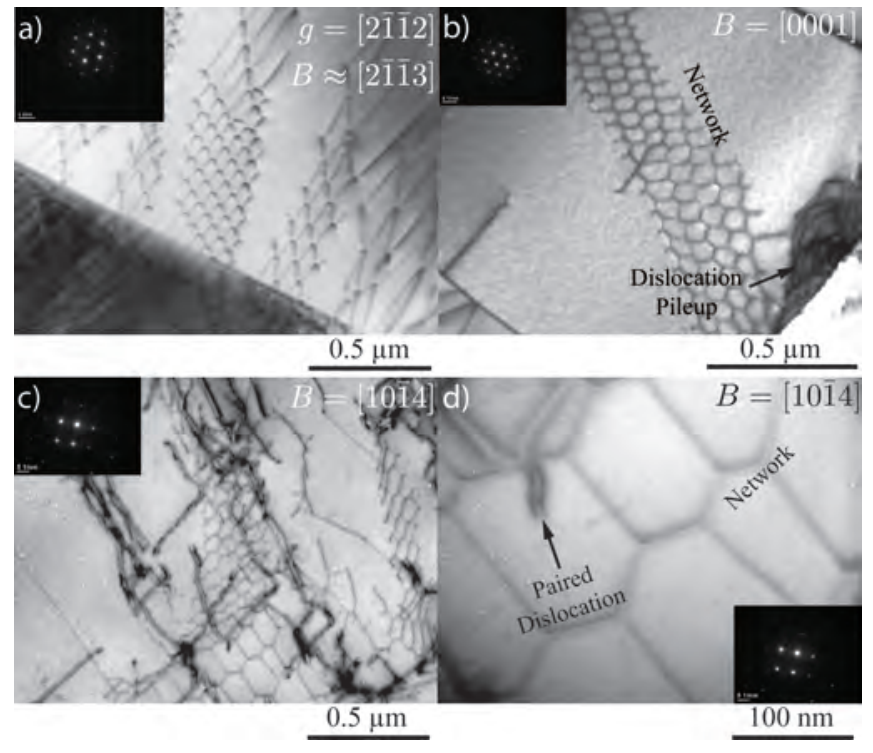

Figure 9: Dislocation network in $\alpha$-Ti grain in the as received material (a). The network is formed by dislocations on different slip planes which were found to be $(0 \overline{1} 10)[2 \overline{1} \overline{1} 0]$,

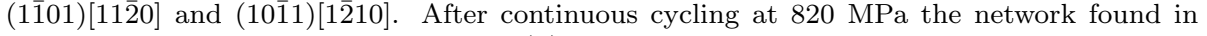
the gauge section remained undeformed (b). After dwell loading the network was observed to unravel (c-d). Around the network edge, $\langle a+c\rangle$-type dislocations accumulate and cross slip along the network. At higher magnification it can be seen that the dislocations in the network are paired $(\mathrm{d})$. 

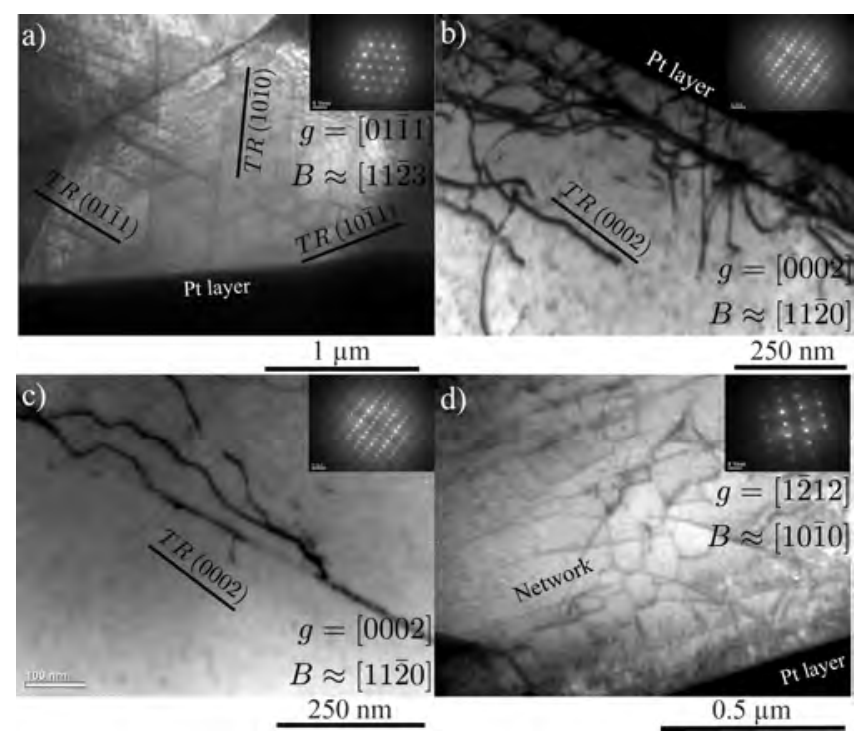

Figure 10: FIB lift out foil of the subsurface initiation facet from the sample cycled continuously at $940 \mathrm{MPa}$. Slip bands along $(0 \overline{1} 10),(10 \overline{1} 0)$ and (1011) of $\langle a\rangle$-type screw dislocations formed (a). Along the fracture surface edge dislocations with $\langle a\rangle$-type Burgers vector formed (b). These edge dislocations lay in the basal plane and were also found close to an adjacent basal plane (c). A distorted network was also found below the fracture surface (d). 


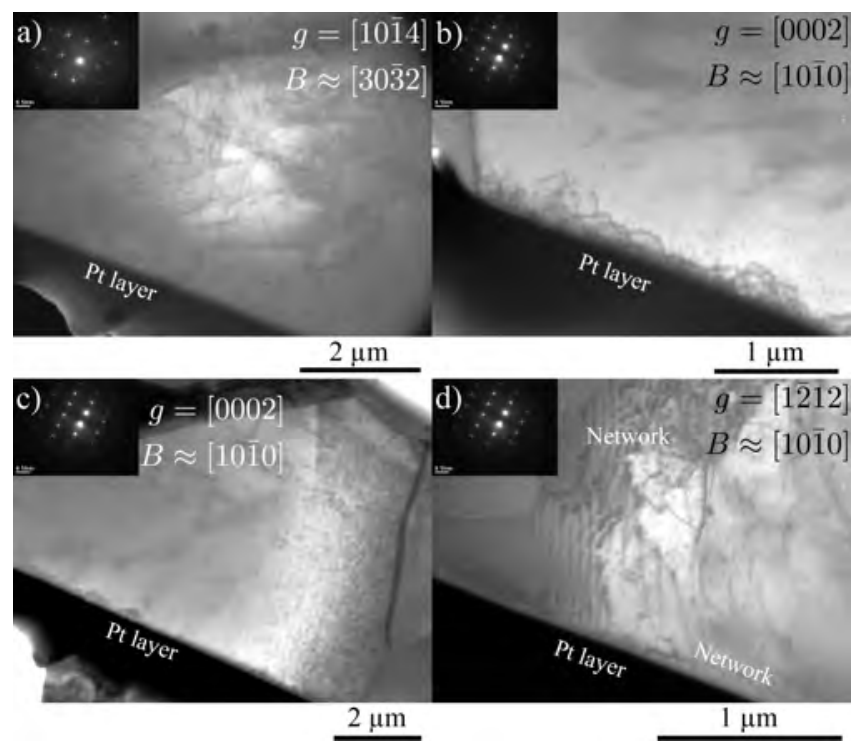

Figure 11: FIB lift out foil of the subsurface initiation facet from the sample cycled continuously at $820 \mathrm{MPa}$. The formation of slip bands could not be seen in overview images (a). Dislocations of edge $\langle a\rangle$ or screw $\langle a+c\rangle$-type dislocations appeared near the surface (b) and sporadically in the bulk of the grain (c). Dislocation networks were found at the fracture surface and also below (d). 


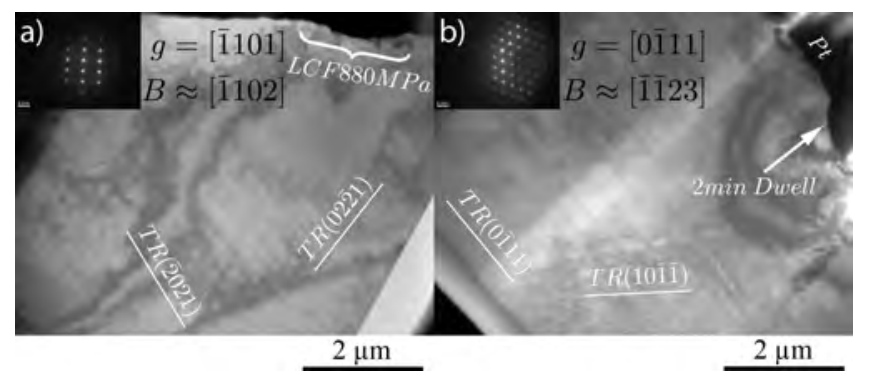

Figure 12: TEM lifted foils of sample LCF 880/820 (a) and LCF/Dwell 880 (b). In both striated grains slip on the pyramidal planes occurred. The change in load regime caused a small deflection of the growing crack in the form of a depression in the LCF 880/820 sample. The 2 minute hold in the LCF/Dwell sample caused the formation of a large step which was found to be $\sim 10$ times larger than the striation height. 


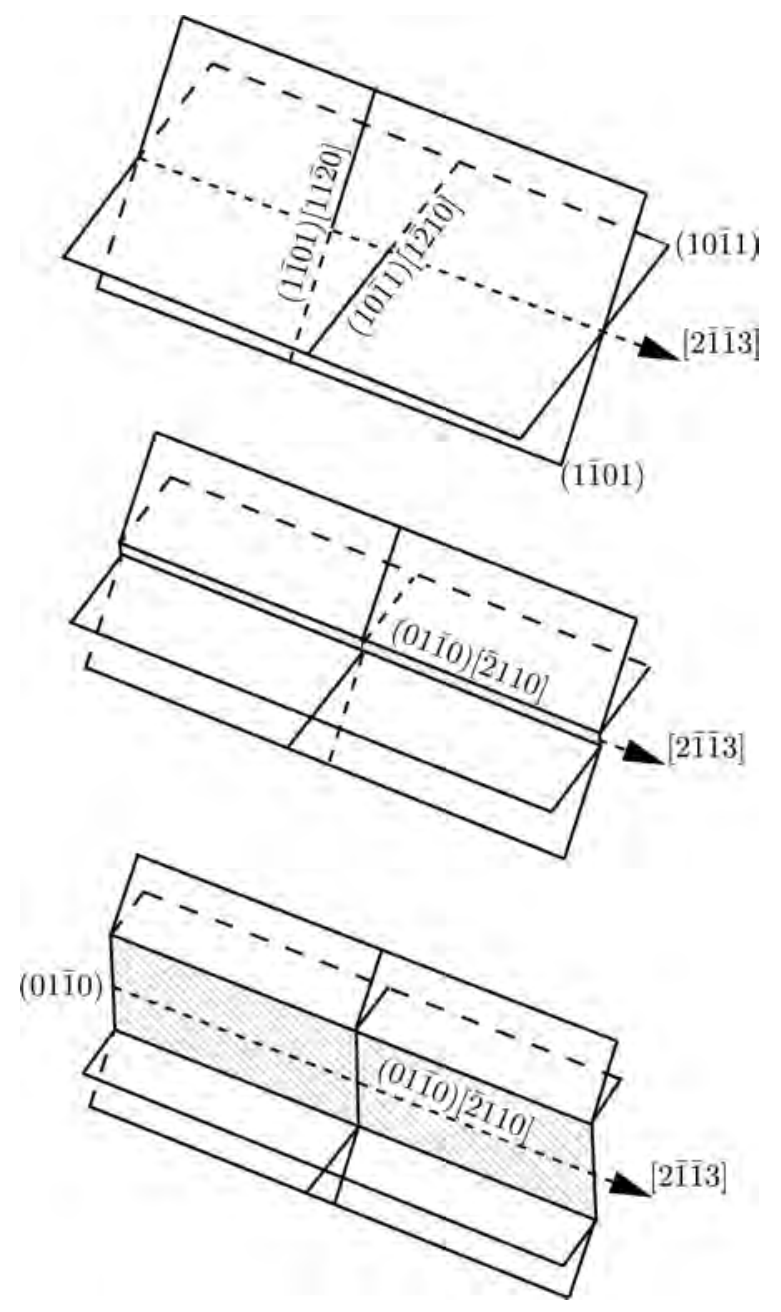

Figure 13: Formation mechanism of a hexagonal dislocation junction which led to the formation of the network shown in Figure 9a. Two dislocations on the (1011) and (1101) planes that are close to each other build a connecting dislocation on the $(0 \overline{1} 10)$ plane. The Burgers vector of the new segment is the sum of the two parent dislocation formed according to the reaction $\frac{1}{3}[11 \overline{2} 0]+\frac{1}{3}[1 \overline{2} 10]=\frac{1}{3}[2 \overline{1} \overline{1} 0]$. The growth of the connecting dislocation reduces the overall dislocation length and hence reduces the stored energy. 


\section{List of Tables}

735

740

1 Summary of the fatigue tests performed. Tests A-D composed simple loading cycles whilst X-Z were composed of alternating LCF and dwell cycles from A-D. The number of cycles, $N$, sustained for each loading type are given, and the total $\Sigma$. The observed number of initiation sites on the fracture surfaces are also given. ${ }^{*}$ indicates the type of initiation site that led to failure. 42

2 Comparison between TEM and QTF/EBSD measurements of the misorientation between the (0002) pole and plane of fracture. . . 43 
Table 1: Summary of the fatigue tests performed. Tests A-D composed simple loading cycles whilst X-Z were composed of alternating LCF and dwell cycles from A-D. The number of cycles, $N$, sustained for each loading type are given, and the total $\Sigma$. The observed number of initiation sites on the fracture surfaces are also given. ${ }^{*}$ indicates the type of initiation site that led to failure.

\begin{tabular}{|c|c|c|c|c|c|c|c|c|}
\hline & \multirow{2}{*}{ Load } & \multirow{2}{*}{$N_{L C F 820}$} & \multirow{2}{*}{$N_{L C F 880}$} & \multirow{2}{*}{$N_{L C F 940}$} & \multirow{2}{*}{$N_{\text {Dwell } 880}$} & \multirow{2}{*}{$\sum$} & \multicolumn{2}{|c|}{ \# Initiation Sites } \\
\hline & & & & & & & Surface & Subsurface \\
\hline A & LCF $880 \mathrm{MPa}$ & 0 & 21843 & 0 & 0 & 21843 & $1^{*}$ & - \\
\hline B & $\mathrm{LCF} 820 \mathrm{MPa}$ & 278908 & 0 & 0 & 0 & 278908 & $1^{*}$ & 1 \\
\hline $\mathrm{C}$ & LCF $940 \mathrm{MPa}$ & 0 & 0 & 9613 & 0 & 9613 & 1 & $1^{*}$ \\
\hline $\mathrm{D}$ & Dwell $880 \mathrm{MPa}$ & 0 & 0 & 0 & 9310 & 9310 & - & $>9^{*}$ \\
\hline $\mathrm{X}$ & $10 \mathrm{~A} / 1 \mathrm{D}$ & 0 & 7349 & 0 & 733 & 8072 & - & $>24^{*}$ \\
\hline $\mathrm{Y}$ & $10 \mathrm{~A} / 40 \mathrm{~B}$ & 50596 & 12650 & 0 & 0 & 63246 & $1^{*}$ & - \\
\hline $\mathrm{Z}$ & $100 \mathrm{~A} / 10 \mathrm{C}$ & 0 & 21642 & 2160 & 0 & 23802 & $1^{*}$ & 2 \\
\hline
\end{tabular}


Table 2: Comparison between TEM and QTF/EBSD measurements of the misorientation between the (0002) pole and plane of fracture.

\begin{tabular}{llll}
\hline \multirow{2}{*}{ Sample } & Surface/ & \multicolumn{2}{c}{ Angle $\left(^{\circ}\right)$} \\
& Subsurface & TEM & QTF/EBSD \\
\hline LCF 880 (A) & Surface & 8.9 & $7.0,12.2$ \\
LCF 820 (B) & Surface & 10.6 & $2.4,10.6$ \\
& Subsurface & 4.2 & $1.8,4.6,7.5$ \\
LCF 940 (C) & Surface & 10.8 & 13.4 \\
Dwell 880 (D) & Subsurface & 3.5 & 3.0 \\
LCF/Dwell 880 (X) & Subsurface & - & 6.3 \\
LCF 880/820 (Y) & Subsurface & - & $8.5,12.3$ \\
LCF 880/940 (Z) & Surface & - & $4.3,7.5$ \\
\hline
\end{tabular}

